\title{
openheart The cardiometabolic benefits of glycine: Is glycine an 'antidote' to dietary fructose?
}

\author{
Mark F McCarty, ${ }^{1}$ James J DiNicolantonio ${ }^{2}$
}

To cite: McCarty MF, DiNicolantonio JJ. The cardiometabolic benefits of glycine: Is glycine an 'antidote' to dietary fructose?. Open Heart 2014;1:e000103. doi:10.1136/openhrt-2014000103

Accepted 26 April 2014

${ }^{1}$ NutriGuard Research, Inc, Encinitas, California, USA

${ }^{2}$ Department of Preventive Cardiology, Saint Luke's Mid America Heart Institute, Kansas City, Missouri, USA

Correspondence to Dr James J DiNicolantonio; jjdinicol@gmail.com

\section{VASCULAR PROTECTIVE PROPERTIES OF SUPPLEMENTAL GLYCINE}

Supplemental glycine, via activation of glycine-gated chloride channels that are expressed on a number of types of cells, including Kupffer cells, macrophages, lymphocytes, platelets, cardiomyocytes and endothelial cells, has been found to exert anti-inflammatory, immunomodulatory, cytoprotective, platelet-stabilising and antiangiogenic effects in rodent studies that may be of clinical relevance. ${ }^{1-17}$ The plasma concentration of glycine in normally nourished individuals-around $200 \mu \mathrm{M}$-is near the $\mathrm{K}_{\mathrm{m}}$ for activation of these channels, implying that the severalfold increases in plasma glycine achievable with practical supplementation can be expected to further activate these channels in vivo. ${ }^{18} 19$ The impact on membrane polarisation of such activation will hinge on the intracellular chloride content; cells which actively concentrate chloride against a gradient will be depolarised by channel activation, whereas other cells will experience hyperpolarisation. In cells that fail to concentrate chloride and that express voltage-activated calcium channels, glycine tends to suppress calcium influx; this effect is thought to mediate much of the protection afforded by glycine. ${ }^{1}$ The role of chloride channel activation in the mediation of glycine's physiological effects is commonly assessed by the concurrent application of the chloride channel inhibitor strychnine; if this abolishes glycine's effect, this effect is most likely mediated by chloride channels.

From the standpoint of vascular health, a recent report that glycine can stabilise platelets is of evident interest. ${ }^{7}$ When rats were fed diets containing $2.5-5 \%$ glycine, bleeding time approximately doubled, and the amplitude of platelet aggregation in whole blood triggered by ADP or collagen was halved. This effect was blocked by strychnine, and the investigators were able to confirm that platelets express glycine- gated chloride channels. They also demonstrated that human platelets likewise were glycine responsive and expressed such channels. Studies evaluating the interaction of glycine with aspirin or other pharmaceutical platelet-stabilising agents would clearly be appropriate, as would a clinical study examining the impact of supplemental glycine on platelet function.

Another recent study has established that cardiomyocytes express chloride channels. ${ }^{17}$ This may rationalise evidence that preadministration of glycine $(500 \mathrm{mg} / \mathrm{kg}$ intraperitoneal $)$ reduces the infarct size by $21 \%$ when rats are subsequently subjected to cardiac ischaemiareperfusion injury; this effect was associated with increases in ventricular ejection fraction and fractional shortening in the glycine pretreated animals as compared with the controls. ${ }^{17}$ This protection was associated with a reduction in cardiomyocyte apoptosis, blunted activation of p38 MAP kinase and JNK and decreased Fas ligand expression. A previous study had reported that $3 \mathrm{mM}$ glycine promoted increased survival of cardiomyocytes in vitro subjected to $1 \mathrm{~h}$ of ischaemia and then reoxygenated, and was also protective in an ex vivo model of cardiac ischaemia reperfusion. ${ }^{20}$

Vascular endothelial cells express glycinegated chloride channels, and it has been suggested that glycine might exert an antiatherosclerotic effect by hyperpolarising the vascular endothelium. ${ }^{19}$ Since such cells do not express voltage-gated calcium channels, the impact of endothelial hyperpolarisation is to increase calcium influx, as calcium follows the charge gradient. ${ }^{21}$ This in turn would be expected to promote the calcium-mediated activation of endothelial nitric oxide synthase. Moreover, endothelial polarisation influences nicotinamide adenine dinucleotide phosphate (NADPH) oxidase activity; this is boosted by depolarisation and conversely inhibited by hyperpolarisation. ${ }^{22-24}$ The vascular-protective impact of potassium-rich diets is suspected to be mediated in part by 
the endothelial hyperpolarisation that results from modest physiological increases in the plasma potassium level (reflecting increased activity of the electrogenic sodium pump). ${ }^{25} 26$ Other factors being equal, an increase in endothelial nitric oxide generation coupled with a decrease in superoxide production could be expected to have an antiatherogenic and antihypertensive effect. Also speaking in favour of the antiatherosclerotic potential for glycine is a study demonstrating that glycine exerts an anti-inflammatory effect on human coronary arterial cells exposed to tumour necrosis factor (TNF) $\alpha$ in vitro; activation of NF-KB was suppressed, as was the expression of E-selectin and interleukin- $6 .{ }^{27}$ So far, there are no published studies evaluating the impact of dietary glycine on atherogenesis in rodent models. Evidence that glycine has an antihypertensive effect in sucrose-fed rats is discussed below.

Glycine is a biosynthetic precursor for creatine, haeme, nucleic acids and the key intracellular antioxidant glutathione. Measures which raise or conserve intracellular glutathione levels may be of benefit from the standpoint of oxidant-mediated mechanisms that impair vascular health. A recent clinical study reports that concurrent supplementation of elderly participants with glycine and cysteine $(100 \mathrm{mg} / \mathrm{kg} /$ day of each, cysteine administered as its $\mathrm{N}$-acetyl derivative) reverses the marked age-related reduction in erythrocyte glutathione levels while lowering the serum markers of oxidative stress $^{28}$; the authors, however, did not prove that the supplemental glycine was crucial for this effect.

With respect to diabetes, it is of interest that high intakes of glycine have the potential to oppose the formation of Amadori products, precursors to the advanced glycation endproducts (AGEs) that mediate diabetic complications. ${ }^{29} 30$ Indeed, supplementation of human diabetics with glycine $-5 \mathrm{~g}, 3-4$ times daily-is reported to decrease haemoglobin glycation. ${ }^{31}{ }^{32}$ A similar effect has been reported in streptozotocin-treated diabetic rats. ${ }^{33}$ These studies did not measure AGEs per se, so their findings should be interpreted cautiously. Nonetheless, glycine supplementation has delayed the progression of cataract, inhibited microaneurysm formation, normalised the proliferative response of blood mononuclear cells and aided the humoral immune response in diabetic rats, effects which suggest that glycine may have potential for prevention of some diabetic complications. ${ }^{34-36}$ In a recent controlled but unblinded study, patients with diabetes experiencing auditory neuropathy achieved improvements in hearing acuity and auditory nerve conduction while ingesting $20 \mathrm{~g}$ glycine daily for 6 months. ${ }^{37}$

\section{GLYCINE AFFORDS PROTECTION FROM} SUCROSE-INDUCED METABOLIC SYNDROME

Of particular interest are studies showing that high glycine intakes can counteract many of the adverse effects of a high-sucrose diet on the liver, adipose mass and vascular function in rats. ${ }^{38} 39$ Glycine decreased the elevated non-esterified fatty acid content of the liver of sucrose-fed rats, increased the state IV oxidation rate of hepatic mitochondria, corrected an elevation of blood pressure, normalised the serum triglycerides and insulin, prevented an increase in abdominal fat mass and, in the vasculature, boosted glutathione, decreased oxidative stress and normalised endothelium-dependent vasodilation. Of likely relevance to these findings is a recent clinical report that supplemental glycine ( $15 \mathrm{~g}$ daily in three divided doses) administered to patients with metabolic syndrome lessened indices of oxidative stress in erythrocytes and leucocytes, while lowering systolic blood pressure. ${ }^{40}$ These findings are of considerable interest, particularly in the light of evidence that high dietary fructose intakes can promote metabolic syndrome and non-alcoholic fatty liver disease in humans and increase LDL cholesterol. ${ }^{41-43}$

The protective effects of glycine in sucrose-fed rats, and in humans with metabolic syndrome, are not readily explained on the basis of the known metabolic effects of glycine. Fructose is known to exert its adverse effects primarily via its impact on liver metabolism; it is catabolised almost exclusively in the liver, and its oxidation, unlike that of glucose, is not regulated by metabolic need. ${ }^{41} 44$ As a result, a high intake of fructose floods the liver with substrate and suppresses hepatic fatty acid oxidation, while promoting de novo lipogenesis and triglyceride synthesis; increased generation of malonyl-coenzyme A is responsible for the first two effects, whereas an increase in glycerol-3-phosphate contributes importantly to fructose's stimulatory impact on triglyceride synthesis. These effects also increase hepatic production of diacylglycerols, which impair hepatic insulin sensitivity via activation of protein kinase $\mathrm{C}-\varepsilon{ }^{45}{ }^{46}$ The increased triglyceride content of fructose-exposed hepatocytes can be expected to stabilise apoB100 and accelerate secretion of very-low-density lipoprotein (VLDL) particles ${ }^{47}{ }^{48}$; this phenomenon may explain the elevation of LDL cholesterol induced by high-fructose intakes. ${ }^{42}$ The increased hepatic secretion of VLDL triglyceride presumably is responsible for the increase in visceral fat observed in rodents and humans fed high-fructose diets. ${ }^{41}$ This in turn can induce metabolic syndrome, including an increase in blood pressure driven in part by hyperinsulinaemia ${ }^{49}$ (figure 1).

There is recent evidence that fructose can also act indirectly to boost hepatic gluconeogenesis. Fructose, but not glucose, can activate AMP kinase (AMPK) in certain regions of the hypothalamus, resulting in increased adrenocortical production of corticosteroids that promote hepatic transcription of phosphoenolpyruvate carboxykinase, rate-limiting for gluconeogenesis. ${ }^{50}$

How does glycine intervene in this process? We propose that glycine-stimulated secretion of glucagonlike peptide-1 (GLP-1) and of glucagon itself plays a key role in this regard. 
Figure 1 Hepatic effects of fructose.
Hepatic Effects of Fructose

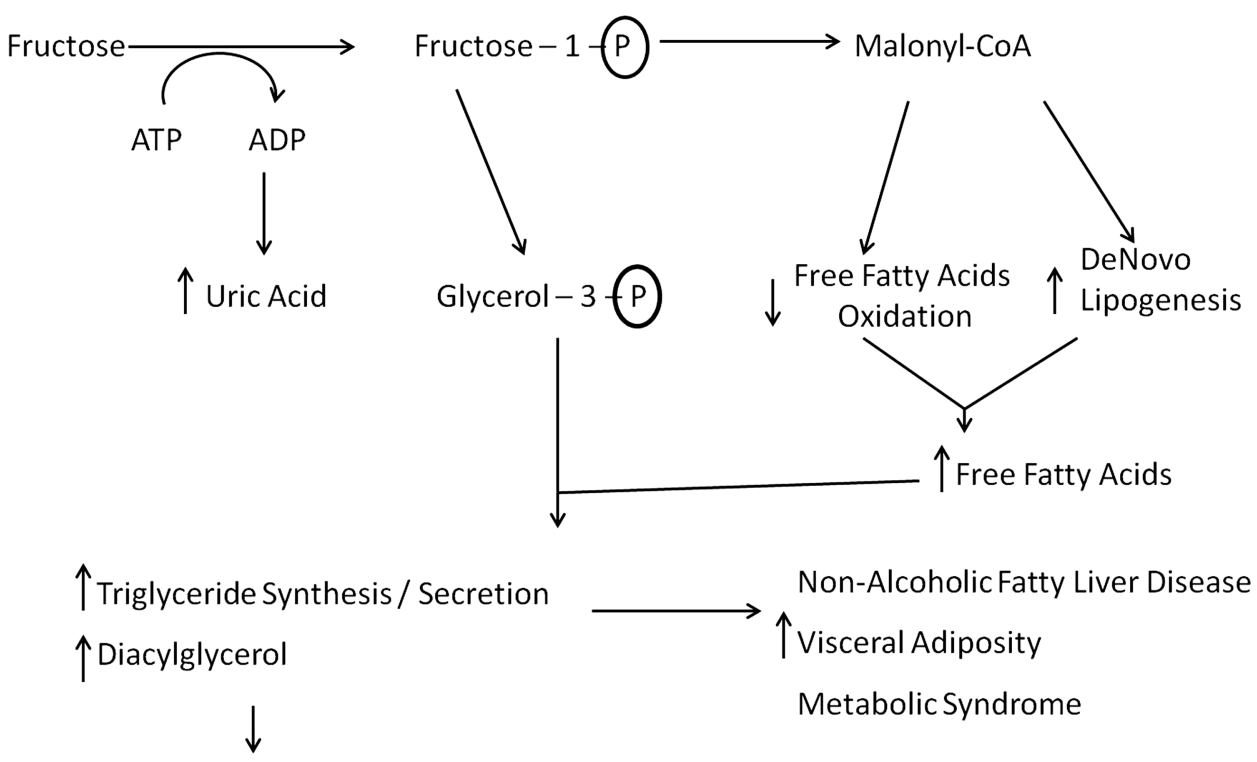

Hepatic Insulin Resistance

\section{GLYCINE MAY STIMULATE GLP-1 AND GLUCAGON RELEASE}

Gameiro et $a l^{51}$ working with the GLUTag cell line derived from intestinal L-cells-the cell type specialised for GLP-1 production in the intestinal mucosa-, have found that glycine provokes an increase of GLP-1 secretion in these cells. This reflects an activation of glycinegated chloride channels that triggers a reduction in membrane polarisation, leading to an increase in cytoplasmic free calcium and a consequent release of GLP-1. The ability of these chloride channels to decrease membrane polarisation in these cells reflects the fact that they concentrate chloride via a $\mathrm{Na}^{+}-\mathrm{K}^{+}-2 \mathrm{Cl}^{-}$transporter. Drugs which inhibit either the glycine-gated channels or the chloride uptake mechanism prevent glycine from stimulating GLP-1 release in GLUTag cells. Since the apical microvilli of L-cells face the intestinal lumen, they are ideally positioned to detect an increase in glycine in the luminal contents. Hence, glycine supplementation could be expected to boost GLP-1 production. Although there do not appear to be any studies that have examined the GLP-1 response to orally administered glycine per se, there are two clinical studies demonstrating that plasma GLP-1 levels rise following ingestion of gelatin, a protein extraordinarily rich in glycine (constituting $30 \%$ of its amino acids). ${ }^{52} 53$ This may explain why, when glucose was fed to patients with type 2 diabetes in conjunction with seven different proteins, gelatin was second only to cottage cheese in potentiating the postprandial insulin response. ${ }^{54}$

Oral administration of glycine in humans $(75 \mathrm{mg}$ glycine $/ \mathrm{kg}$ lean mass) has also been reported to stimulate an increase in glucagon secretion by pancreatic $\alpha$-cells. ${ }^{55}$ This response is negated if glucose is ingested simultaneously, most likely reflecting the impact of glucose-evoked secretion of somatostatin from islet $\delta$-cells. ${ }^{56}$ The contention that oral glycine stimulates GLP-1 production is difficult to square with glycine's impact on glucagon, as GLP-1 is known to inhibit $\alpha$-cell glucagon secretion, either directly or by provoking $\delta$-cell secretion of somatostatin. ${ }^{57}$ However, there is recent evidence that glycine may act directly on $\alpha$-cells as a glucagon secretagogue-and perhaps this effect overrides that of GLP-1 (the impact of GLP-1 on somatostatin secretion might be minor when glucose is at basal levels, and that of GLP-1 receptor expression on $\alpha$-cells is very low $\left.{ }^{57}\right)$. Li et $a \bar{p}^{8}$ have shown that $\alpha$-cells express glycine-gated chloride channels that, when activated, trigger an influx of calcium and glucagon release. This suggests that $\alpha$-cells, like L-cells, have a mechanism for concentrating chloride intracellularly, such that a receptor-mediated increase in membrane permeability triggers chloride efflux and membrane depolarisation. Since the affinity of glycine-gated channels for glycine is close to the fasting concentration of glycine in plasma, ${ }^{51}$ it can be anticipated that a rise in plasma glycine induced via supplementation will cause an increase in glucagon secretion. One rather old study failed to observe an increase in glucagon secretion when glycine was infused intravenously, until the glycine reached supraphysiological levels $^{59}$; it is not clear why the results of this study appear discordant with those of the two studies previously cited.

It is notable that GLP-1 and glucagon work in complementary ways to promote fatty acid oxidation and oppose lipogenesis in the liver. ${ }^{60-65}$ The effects of 
glucagon appear to be mediated primarily by cAMP, whereas GLP-1 triggers activation of AMPK in hepatocytes. Joint action of GLP-1 and glucagon on the liver could readily account for the ability of supplemental glycine to counteract the excessive hepatic triglyceride synthesis promoted by sucrose or fructose feeding (see figure 2). Indeed, GLP-1 agonists have been shown to protect against hepatic steatosis in sucrose-fed rats, and to have clinical utility in non-alcoholic fatty liver disease ${ }^{66-70}$ Fortuitously, although glucagon could be expected to promote hepatic gluconeogenesis, GLP-1 mediated AMPK activation would tend to offset this effect. ${ }^{71}$ Indeed, AMPK suppresses the transcription of phosphoenolpyruvate carboxykinase in the liver, potentially offsetting the stimulatory impact of fructose-evoked cortisol in this regard. ${ }^{72-74}$

Intriguingly, peptide drugs with dual agonism for GLP-1 and glucagon receptors have been developed recently, and these agents have shown markedly beneficial effects in mice with diet-induced obesity. ${ }^{75-77}$ They can induce a weight loss of 15-20\%, modestly decrease calorie intake while boosting thermogenesis, decrease hepatic triglyceride levels and serum levels of triglycerides and LDL cholesterol, improve insulin sensitivity and glucose tolerance and counteract leptin resistance. These beneficial metabolic effects are only partially attributable to the associated weight loss and are considerably greater than the benefits seen with GLP-1 agonists alone. These agents provide continual stimulation of their target receptors, and hence understandably achieve more potent effects than dietary glycine, which at best could only boost GLP-1 and glucagon levels episodically. Nonetheless, while glycine does not induce weight loss or suppress calorie intake in sucrose-fed mice, it reduces visceral fat stores by over $50 \%$, increases the thermogenic potential of hepatic mitochondria by increasing state 4 respiration, alleviates hepatic steatosis and improves insulin sensitivity and serum lipids. Hence, its effects are homologous to, if not as dramatic, as those seen with the coagonist drugs.

\section{FURTHER IMPLICATIONS OF GLP-1 UPREGULATION}

If supplemental glycine does indeed boost secretion of GLP-1, this may have interesting implications for the prevention and treatment of diabetes, and for the preservation of vascular health. As is well known, GLP-1 functions to potentiate glucose-stimulated insulin secretion, and this is the basis for the therapeutic utility in diabetes of analogues of GLP-1 such as liraglutide and exenatide which activate the GLP-1 receptor but have a vastly longer half-life owing to their resistance to degradation by dipeptidyl protease-4 (DDP-4) ${ }^{78}$ Endogenously produced GLP-1 has a half-life of only several minutes in plasma owing to its rapid degradation by DDP-4; hence, drugs which can safely inhibit DDP-4, such as sitagliptin, are currently employed to prolong the efficacy of endogenously produced GLP-1 in patients with diabetes. ${ }^{79}$ If supplemental glycine does indeed boost GLP-1 production, it presumably could be used as an adjuvant to DDP-4 therapy, and, as a stand-alone measure, might have some potential for the primary prevention of diabetes.

Moreover, if supplemental glycine can promote a physiologically meaningful increase in GLP-1 production, it may have broader protective potential than is currently appreciated, reflecting the diverse and largely protective physiological effects of GLP- $1{ }^{80}$ With respect to vascular health, GLP-1 agonist drugs exert cardioprotective effects in rodent models of myocardial infarction and congestive failure. ${ }^{81-84}$ Clinically, they promote modest weight loss in patients with diabetes and obese non- diabeties, and exert favourable effects on systolic blood pressure, serum lipids, inflammatory markers and endothelial function. ${ }^{85}$ Readers interested in the vascular-protective properties of GLP-1 agonism can be referred to a recent review by Lorber. ${ }^{86}$ Assessing the impact of supplemental glycine on GLP-1 production should be a high clinical priority.

\section{AN IMPACT ON KUPFFER CELL ACTIVATION}

The marked utility of dietary glycine in rodent models of alcohol-induced steatosis has been traced to its ability to suppress Kupffer cell activation. ${ }^{9}{ }^{87}$ Ethanol feeding, by promoting intestinal permeability, enables portal influx of bacterial endotoxins. The resulting activation of Kupffer cells exposes hepatocytes to proinflammatory cytokines such as TNF- $\alpha$ that play a key role in induction of steatohepatitis. Glycine antagonises Kupffer cell activation via glycine-gated channels, as previously discussed.

There is some recent evidence that high-fructose diets in rats likewise impair the intestinal barrier function, leading to an activation of Kupffer cells that exacerbates fructose-induced steatosis. ${ }^{88-90}$ It is reasonable to suspect that a high-glycine diet would be protective in this regard, as it is in rodent models of alcohol-induced steatosis. Whether Kupffer cell activation plays a role in the hepatic steatosis evoked by high-fructose diets in humans remains to be established.

Fortunately, glycine powder is inexpensive, highly soluble and has a pleasant sweet flavor; indeed, its name is derived from the Greek work for 'sweet'. ${ }^{16}$ Clinically useful effects have been observed in patients with metabolic syndrome or diabetes with glycine intakes of $5 \mathrm{~g}$, 3-4 times daily, without discernible side effects. ${ }^{32}$ 40 Glycine is readily administered by blending into a fluid of choice, and it should lend itself well to incorporation into functional foods. Glycine intake can also be boosted by ingestion of gelatin.

\section{IS URIC ACID A MEDIATING RISK FACTOR?}

The proposal that glycine might function as an 'antidote' to the adverse metabolic impact of fructose must contend with the fact that fructose can markedly amplify 
Hepatoprotective Mechanisms of Glycine

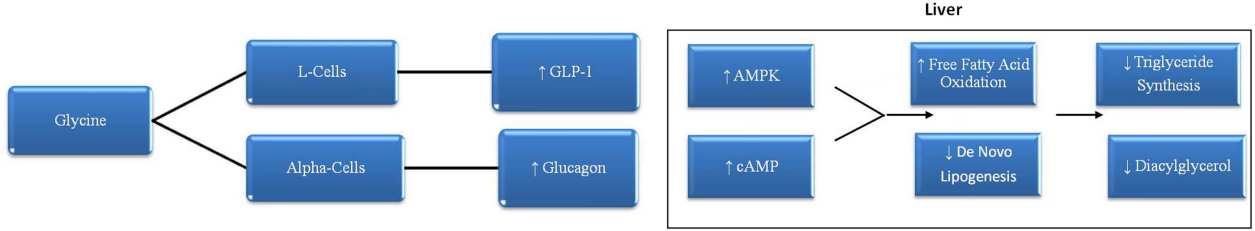

Figure 2 Hepatoprotective mechanisms of glycine.

production of uric acid in the liver. Administration of a bolus of fructose leads to the rapid hepatic generation of ADP owing to the unregulated activity of fructokinase; this in turn can lead to accelerated production of AMP, adenosine and purine catabolites-including the ultimate catabolite (in humans) uric acid. The ability of fructose-rich diets to boost serum urate levels is well known, and there is no reason to suppose that glycine would prevent this effect. This urate does not pose a problem in fructose-fed rodents, as their uricase activity converts urate to non-toxic allantoin-but humans do not express uricase. Human physiological levels of urate are clearly toxic to the tissues of rodents, as they promote oxidative stress via NADPH oxidase activation. $^{91-93}$

Increased urate levels in humans, in addition to posing a risk for gout or gouty nephropathy, constitute a well-established risk factor for coronary disease, hypertension, type 2 diabetes and heart failure, as confirmed by meta-analyses ${ }^{94-98}$ _although its impact often appears weak when other risk factors associated with metabolic syndrome are corrected for. Whether uric acid is a mediating risk factor in these disorders is very much in dispute. Speaking in favour of this view are studies demonstrating that xanthine oxidase inhibition with allopurinol often favourably influences endothelial dysfunction $^{99-101}$; however, a counterargument is that xanthine oxidase activity generates superoxide, so allopurinol may simply be functioning as an antioxidant in these circumstances. ${ }^{102}$

Moreover, several studies in which urate levels have been modulated acutely by measures other than xanthine oxidase inhibition-raising it with an intravenous infusion, lowering it with an infusion of urate oxidasehave failed to observe any adverse impact of urate on endothelial function or other cardiovascular indices. $^{103} 104$ Indeed, urate infusion was found to improve endothelial function in patients with type 1 diabetes, possibly reflecting the utility of urate as a peroxynitrite scavenger. ${ }^{105}$ The long-term marked elevation of urate with supplemental inosine-being studied in patients with multiple sclerosis as an antioxidant strategy -failed to influence blood pressure. ${ }^{106}$ Perhaps most compellingly, a number of recent Mendelian randomisation analyses, focusing on polymorphisms of renal tubular transport proteins for urate that influence serum urate levels, have failed to observe any impact of these polymorphisms on risk for heart disease, subclinical atherosclerosis, diabetes, hypertension, metabolic syndrome or diabetes ${ }^{107-111}$ — with the exception of one small study targeting an Amish population which saw an association with blood pressure. ${ }^{112}$ The overall conclusion of these studies is that obesity and metabolic syndrome raise the serum urate level, and that the former, rather than urate per se, mediates the increased risk associated with elevated urate levels. The hyperinsulinaemia associated with metabolic syndrome promotes renal retention of urate, explaining at least in part the hyperuricaemia that is a feature of this syndrome. ${ }^{113}$ It appears that primates have evolved resistance to the pro-oxidant effects of urate demonstrated in rodents, such that losing their uricase activity did not compromise their Darwinian viability.

Hence, the failure of glycine to address the fructose-mediated elevation of serum urate levels, while unfortunate from the standpoint of gout risk, may not be disadvantageous from the standpoint of vascular health. Elevated urate levels appear likely to provide some protection from Parkinson's disease-a finding confirmed by a Mendelian randomisation analysis. ${ }^{114} 115$

Contributors MFM and JJD came up with the idea for the manuscript. MFM wrote the first draft. JJD reviewed, edited and contributed to concepts in the manuscript.

Competing interests None.

Provenance and peer review Not commissioned; internally peer reviewed.

Open Access This is an Open Access article distributed in accordance with the Creative Commons Attribution Non Commercial (CC BY-NC 3.0) license, which permits others to distribute, remix, adapt, build upon this work noncommercially, and license their derivative works on different terms, provided the original work is properly cited and the use is non-commercial. See: http:// creativecommons.org/licenses/by-nc/3.0/

\section{REFERENCES}

1. Zhong Z, Wheeler MD, Li X, et al. L-glycine: a novel antiinflammatory, immunomodulatory, and cytoprotective agent. Curr Opin Clin Nutr Metab Care 2003;6:229-40.

2. Ikejima K, Qu W, Stachlewitz RF, et al. Kupffer cells contain a glycine-gated chloride channel. Am J Physiol 1997;272(6 Pt 1): G1581-6.

3. Wheeler M, Stachlewitz RF, Yamashina S, et al. Glycine-gated chloride channels in neutrophils attenuate calcium influx and superoxide production. FASEB J 2000;14:476-84.

4. Wheeler MD, Thurman RG. Production of superoxide and TNF-alpha from alveolar macrophages is blunted by glycine. $A m \mathrm{~J}$ Physiol 1999;277(5 Pt 1):L952-9.

5. Froh M, Thurman RG, Wheeler MD. Molecular evidence for a glycine-gated chloride channel in macrophages and leukocytes. Am J Physiol Gastrointest Liver Physiol 2002;283:G856-63. 
6. Yamashina S, Konno A, Wheeler MD, et al. Endothelial cells contain a glycine-gated chloride channel. Nutr Cancer 2001;40:197-204.

7. Schemmer $\mathrm{P}$, Zhong Z, Galli U, et al. Glycine reduces platelet aggregation. Amino Acids 2013;44:925-31.

8. Rose ML, Madren J, Bunzendahl $\mathrm{H}$, et al. Dietary glycine inhibits the growth of B16 melanoma tumors in mice. Carcinogenesis 1999;20:793-8.

9. Yin M, Ikejima K, Arteel GE, et al. Glycine accelerates recovery from alcohol-induced liver injury. J Pharmacol Exp Ther 1998;286:1014-19.

10. Rose ML, Cattley RC, Dunn C, et al. Dietary glycine prevents the development of liver tumors caused by the peroxisome proliferator WY-14,643. Carcinogenesis 1999;20:2075-81.

11. Yin M, Zhong Z, Connor HD, et al. Protective effect of glycine on renal injury induced by ischemia-reperfusion in vivo. Am J Physiol Renal Physiol 2002;282:F417-23.

12. Wheeler MD, Rose ML, Yamashima S, et al. Dietary glycine blunts lung inflammatory cell influx following acute endotoxin. $A m \mathrm{~J}$ Physiol Lung Cell Mol Physiol 2000;279:L390-8.

13. Li X, Bradford BU, Wheeler MD, et al. Dietary glycine prevents peptidoglycan polysaccharide-induced reactive arthritis in the rat: role for glycine-gated chloride channel. Infect Immun 2001;69:5883-91.

14. Senthilkumar R, Nalini N. Glycine prevents hepatic fibrosis by preventing the accumulation of collagen in rats with alcoholic liver injury. Pol J Pharmacol 2004;56:121-8.

15. Ham DJ, Murphy KT, Chee A, et al. Glycine administration attenuates skeletal muscle wasting in a mouse model of cancer cachexia. Clin Nutr 2014;33:448-58.

16. Wang W, Wu Z, Dai Z, et al. Glycine metabolism in animals and humans: implications for nutrition and health. Amino Acids 2013;45:463-77

17. Zhong X, Li X, Qian L, et al. Glycine attenuates myocardial ischemia-reperfusion injury by inhibiting myocardial apoptosis in rats. J Biomed Res 2012;26:346-54.

18. Lynch JW. Molecular structure and function of the glycine receptor chloride channel. Physiol Rev 2004;84:1051-95.

19. McCarty MF, Barroso-Aranda J, Contreras F. The hyperpolarizing impact of glycine on endothelial cells may be anti-atherogenic. Med Hypotheses 2009;73:263-4.

20. Ruiz-Meana M, Pina P, Garcia-Dorado D, et al. Glycine protects cardiomyocytes against lethal reoxygenation injury by inhibiting mitochondrial permeability transition. J Physiol 2004;558(Pt 3):873-82

21. Busse R, Luckhoff A, Mulsch A. Cellular mechanisms controlling EDRF/NO formation in endothelial cells. Basic Res Cardiol 1991;86 (Suppl 2):7-16.

22. Sohn HY, Keller M, Gloe T, et al. The small G-protein Rac mediates depolarization-induced superoxide formation in human endothelial cells. J Biol Chem 2000;275:18745-50.

23. Matsuzaki I, Chatterjee S, Debolt K, et al. Membrane depolarization and NADPH oxidase activation in aortic endothelium during ischemia reflect altered mechanotransduction. Am J Physiol Heart Circ Physiol 2005;288:H336-43.

24. McCabe RD, Bakarich MA, Srivastava K, et al. Potassium inhibits free radical formation. Hypertension 1994;24:77-82.

25. Young DB, Lin H, McCabe RD. Potassium's cardiovascular protective mechanisms. Am J Physiol 1995;268(4 Pt 2):R825-37.

26. McCarty MF. Endothelial membrane potential regulates production of both nitric oxide and superoxide - a fundamental determinant of vascular health. Med Hypotheses 1999;53:277-89.

27. Hasegawa S, Ichiyama T, Sonaka I, et al. Cysteine, histidine and glycine exhibit anti-inflammatory effects in human coronary arterial endothelial cells. Clin Exp Immunol 2012;167:269-74.

28. Sekhar RV, Patel SG, Guthikonda AP, et al. Deficient synthesis of glutathione underlies oxidative stress in aging and can be corrected by dietary cysteine and glycine supplementation. Am J Clin Nutr 2011;94:847-53.

29. Ramakrishnan S, Sulochana KN. Decrease in glycation of lens proteins by lysine and glycine by scavenging of glucose and possible mitigation of cataractogenesis. Exp Eye Res 1993;57:623-8.

30. Ramakrishnan S, Sulochana KN, Punitham R. Free lysine, glycine, alanine, glutamic acid and aspartic acid reduce the glycation of human lens proteins by galactose. Indian J Biochem Biophys 1997;34:518-23.

31. Carvajal SG, Medina SR, Juarez E, et al. Effect of glycine on hemoglobin glycation in diabetic patients. Proc West Pharmacol Soc 1999;42:31-2.
32. Cruz M, Maldonado-Bernal C, Mondragon-Gonzalez R, et al. Glycine treatment decreases proinflammatory cytokines and increases interferon-gamma in patients with type 2 diabetes. $J$ Endocrinol Invest 2008;31:694-9.

33. Carvajal SG, Juarez E, Ramos MG, et al. Inhibition of hemoglobin glycation with glycine in induced diabetes mellitus in rats. Proc West Pharmacol Soc 1999;42:35-6.

34. Alvarado-Vasquez N, Lascurain R, Ceron E, et al. Oral glycine administration attenuates diabetic complications in streptozotocin -induced diabetic rats. Life Sci 2006;79:225-32.

35. Lezcano MD, Teran OL, Carvajal SG, et al. Effect of glycine on the immune response of the experimentally diabetic rats. Rev Alerg Mex 2006;53:212-16.

36. Bahmani F, Bathaie SZ, Aldavood SJ, et al. Glycine therapy inhibits the progression of cataract in streptozotocin-induced diabetic rats. Mol Vis 2012;18:439-48

37. Munoz-Carlin ML, Rodriguez-Moctezuma JR, Gomez Latorre JG, et al. [Effects of glycine on auditory evoked potentials among diabetic patients with auditory pathway neuropathy]. Rev Med Chil 2010;138:1246-52.

38. El HM, Perez I, Zamora J, et al. Glycine intake decreases plasma free fatty acids, adipose cell size, and blood pressure in sucrose-fed rats. Am J Physiol Regul Integr Comp Physiol 2004;287:R1387-93.

39. Ruiz-Ramirez A, Ortiz-Balderas E, Cardozo-Saldana G, et al. Glycine restores glutathione and protects against oxidative stress in vascular tissue from sucrose-fed rats. Clin Sci (Lond) 2014;126:19-29.

40. Diaz-Flores M, Cruz M, Duran-Reyes G, et al. Oral supplementation with glycine reduces oxidative stress in patients with metabolic syndrome, improving their systolic blood pressure. Can J Physiol Pharmacol 2013:91:855-60.

41. Stanhope KL, Schwarz JM, Keim NL, et al. Consuming fructose-sweetened, not glucose-sweetened, beverages increases visceral adiposity and lipids and decreases insulin sensitivity in overweight/obese humans. J Clin Invest 2009;119:1322-34.

42. Zhang $\mathrm{YH}, \mathrm{An} \mathrm{T}$, Zhang $\mathrm{RC}$, et al. Very high fructose intake increases serum LDL-cholesterol and total cholesterol: a meta-analysis of controlled feeding trials. J Nutr 2013;143:1391-8.

43. Basaranoglu M, Basaranoglu G, Sabuncu T, et al. Fructose as a key player in the development of fatty liver disease. World $J$ Gastroentero/ 2013;19:1166-72.

44. Stanhope KL, Schwarz JM, Havel PJ. Adverse metabolic effects of dietary fructose: results from the recent epidemiological, clinical, and mechanistic studies. Curr Opin Lipidol 2013;24:198-206.

45. Jornayvaz FR, Shulman GI. Diacylglycerol activation of protein kinase cepsilon and hepatic insulin resistance. Cell Metab 2012;15:574-84.

46. Chan SM, Sun RQ, Zeng XY, et al. Activation of PPARalpha ameliorates hepatic insulin resistance and steatosis in high fructose-fed mice despite increased endoplasmic reticulum stress. Diabetes 2013;62:2095-105.

47. Boren J, Rustaeus S, Wettesten M, et al. Influence of triacylglycerol biosynthesis rate on the assembly of apoB-100-containing lipoproteins in Hep G2 cells. Arterioscler Thromb 1993; 13:1743-54.

48. Julius $U$. Influence of plasma free fatty acids on lipoprotein synthesis and diabetic dyslipidemia. Exp Clin Endocrinol Diabetes 2003;111:246-50.

49. Reaven GM, Lithell H, Landsberg L. Hypertension and associated metabolic abnormalities - the role of insulin resistance and the sympathoadrenal system. N Engl J Med 1996;334:374-81.

50. Kinote A, Faria JA, Roman EA, et al. Fructose-induced hypothalamic AMPK activation stimulates hepatic PEPCK and gluconeogenesis due to increased corticosterone levels. Endocrinology 2012;153:3633-45.

51. Gameiro A, Reimann F, Habib AM, et al. The neurotransmitters glycine and GABA stimulate glucagon-like peptide-1 release from the GLUTag cell line. J Physiol 2005;569(Pt 3):761-72.

52. Karamanlis A, Chaikomin R, Doran S, et al. Effects of protein on glycemic and incretin responses and gastric emptying after oral glucose in healthy subjects. Am J Clin Nutr 2007;86:1364-8.

53. Rubio IG, Castro G, Zanini AC, et al. Oral ingestion of a hydrolyzed gelatin meal in subjects with normal weight and in obese patients: postprandial effect on circulating gut peptides, glucose and insulin. Eat Weight Disord 2008;13:48-53.

54. Gannon MC, Nuttall FQ, Neil BJ, et al. The insulin and glucose responses to meals of glucose plus various proteins in type II diabetic subjects. Metabolism 1988;37:1081-8.

55. Gannon MC, Nuttall JA, Nuttall FQ. The metabolic response to ingested glycine. Am J Clin Nutr 2002;76:1302-7. 
56. Hauge-Evans AC, King AJ, Carmignac D, et al. Somatostatin secreted by islet delta-cells fulfills multiple roles as a paracrine regulator of islet function. Diabetes 2009;58:403-11.

57. De Marinis YZ, Salehi A, Ward CE, et al. GLP-1 inhibits and adrenaline stimulates glucagon release by differential modulation of $\mathrm{N}$ - and L-type Ca2+ channel-dependent exocytosis. Cell Metab 2010;11:543-53.

58. Li C, Liu C, Nissim I, et al. Regulation of glucagon secretion in normal and diabetic human islets by gamma-hydroxybutyrate and glycine. J Biol Chem 2013;288:3938-51.

59. Muller WA, Aoki TT, Cahill GF Jr. Effect of alanine and glycine on glucagon secretion in postabsorptive and fasting obese man. J Clin Endocrinol Metab 1975;40:418-25.

60. Ben-Shlomo S, Zvibel I, Shnell M, et al. Glucagon-like peptide-1 reduces hepatic lipogenesis via activation of AMP-activated protein kinase. J Hepatol 2011;54:1214-23.

61. Svegliati-Baroni G, Saccomanno S, Rychlicki C, et al. Glucagon-like peptide-1 receptor activation stimulates hepatic lipid oxidation and restores hepatic signalling alteration induced by a high-fat diet in nonalcoholic steatohepatitis. Liver Int 2011;31:1285-97.

62. Lee J, Hong SW, Chae SW, et al. Exendin-4 improves steatohepatitis by increasing Sirt1 expression in high-fat diet-induced obese C57BL/6J mice. PLoS ONE 2012;7:e31394.

63. Louet JF, Hayhurst G, Gonzalez FJ, et al. The coactivator PGC-1 is involved in the regulation of the liver carnitine palmitoyltransferase gene expression by CAMP in combination with HNF4 alpha and cAMP-response element-binding protein (CREB). J Biol Chem 2002;277:37991-8000.

64. Lane MD, Watkins PA, Meredith MJ. Hormonal regulation of acetyl-CoA carboxylase activity in the liver cell. CRC Crit Rev Biochem 1979;7:121-41.

65. Hayden LJ, Cohen S, Levin K, et al. Comparison of glucagon, cAMP, and cGMP effects on lipogenesis in hepatocytes. Can $J$ Biochem Cell Biol 1983;61:207-13.

66. Mells JE, Fu PP, Sharma S, et al. Glp-1 analog, liraglutide, ameliorates hepatic steatosis and cardiac hypertrophy in C57BL/6J mice fed a Western diet. Am J Physiol Gastrointest Liver Physiol 2012;302:G225-35.

67. Sharma S, Mells JE, Fu PP, et al. GLP-1 analogs reduce hepatocyte steatosis and improve survival by enhancing the unfolded protein response and promoting macroautophagy. PLOS ONE 2011;6:e25269.

68. Lee J, Hong SW, Rhee EJ, et al. GLP-1 receptor agonist and non-alcoholic fatty liver disease. Diabetes Metab J 2012;36:262-7.

69. Cuthbertson DJ, Irwin A, Gardner CJ, et al. Improved glycaemia correlates with liver fat reduction in obese, type 2 diabetes, patients given glucagon-like peptide-1 (GLP-1) receptor agonists. PLOS ONE 2012;7:e50117.

70. Olaywi M, Bhatia T, Anand S, et al. Novel anti-diabetic agents in non-alcoholic fatty liver disease: a mini-review. Hepatobiliary Pancreat Dis Int 2013;12:584-8.

71. Viollet B, Guigas B, Leclerc J, et al. AMP-activated protein kinase in the regulation of hepatic energy metabolism: from physiology to therapeutic perspectives. Acta Physiol (Oxf) 2009;196:81-98.

72. Kim YD, Park KG, Lee YS, et al. Metformin inhibits hepatic gluconeogenesis through AMP-activated protein kinase-dependent regulation of the orphan nuclear receptor SHP. Diabetes 2008;57:306-14

73. Andreelli F, Foretz M, Knauf $C$, et al. Liver adenosine monophosphate-activated kinase-alpha2 catalytic subunit is a key target for the control of hepatic glucose production by adiponectin and leptin but not insulin. Endocrinology 2006;147:2432-41.

74. Horike N, Sakoda H, Kushiyama A, et al. AMP-activated protein kinase activation increases phosphorylation of glycogen synthase kinase 3beta and thereby reduces CAMP-responsive element transcriptional activity and phosphoenolpyruvate carboxykinase $C$ gene expression in the liver. J Biol Chem 2008;283:33902-10.

75. Day JW, Ottaway N, Patterson JT, et al. A new glucagon and GLP-1 co-agonist eliminates obesity in rodents. Nat Chem Bio 2009;5:749-57.

76. Patel V, Joharapurkar A, Dhanesha N, et al. Co-agonist of glucagon and GLP-1 reduces cholesterol and improves insulin sensitivity independent of its effect on appetite and body weight in diet-induced obese C57 mice. Can J Physiol Pharmacol 2013:91:1009-15.

77. Clemmensen C, Chabenne J, Finan B, et al. GLP-1/glucagon co-agonism restores leptin responsiveness in obese mice chronically maintained on an obesogenic diet. Diabetes 2014;63:1422-7.
78. Cho YM, Wideman RD, Kieffer TJ. Clinical application of glucagon-like peptide 1 receptor agonists for the treatment of type 2 diabetes mellitus. Endocrinol Metab (Seoul) 2013;28:262-74.

79. Campbell RK. Rationale for dipeptidyl peptidase 4 inhibitors: a new class of oral agents for the treatment of type 2 diabetes mellitus. Ann Pharmacother 2007:41:51-60.

80. Seufert J, Gallwitz B. The extra-pancreatic effects of GLP-1 receptor agonists: a focus on the cardiovascular, gastrointestinal and central nervous systems. Diabetes Obes Metab 2013.

81. Fields AV, Patterson B, Karnik AA, et al. Glucagon-like peptide-1 and myocardial protection: more than glycemic control. Clin Cardiol 2009;32:236-43.

82. Ravassa S, Zudaire A, Diez J. Glucagon-like peptide 1 and cardiac cell survival. Endocrinol Nutr 2012;59:561-9.

83. Angeli FS, Shannon RP. Incretin based therapies: can we achieve glycemic control and cardioprotection? J Endocrinol 2014;221: T17-30.

84. Clarke SJ, McCormick LM, Dutka DP. Optimising cardioprotection during myocardial ischaemia: targeting potential intracellular pathways with glucagon-like peptide-1. Cardiovasc Diabetol 2014;13:12.

85. Vilsboll T, Christensen M, Junker AE, et al. Effects of glucagon-like peptide-1 receptor agonists on weight loss: systematic review and meta-analyses of randomised controlled trials. BMJ 2012;344 d7771.

86. Lorber D. GLP-1 receptor agonists: effects on cardiovascular risk reduction. Cardiovasc Ther 2013;31:238-49.

87. Yamashina S, Ikejima K, Enomoto N, et al. Glycine as a therapeutic immuno-nutrient for alcoholic liver disease. Alcohol Clin Exp Res 2005;29(11 Suppl):162S-5S

88. Spruss A, Kanuri G, Wagnerberger $\mathrm{S}$, et al. Toll-like receptor 4 is involved in the development of fructose-induced hepatic steatosis in mice. Hepatology 2009;50:1094-104.

89. Spruss A, Kanuri G, Stahl C, et al. Metformin protects against the development of fructose-induced steatosis in mice: role of the intestinal barrier function. Lab Invest 2012;92:1020-32.

90. Zhu ML, Liu J, Liu YL, et al. [Activation of Kupffer cell and related signal pathway proteins in the liver of high fat and high fructose diet induced NAFLD mice]. Zhonghua Shi Yan He Lin Chuang Bing Du Xue Za Zhi 2013;27:325-7.

91. Sautin YY, Nakagawa T, Zharikov S, et al. Adverse effects of the classic antioxidant uric acid in adipocytes: NADPH oxidase-mediated oxidative/nitrosative stress. Am J Physiol Cell Physiol 2007;293: C584-96.

92. Sanchez-Lozada LG, Soto V, Tapia E, et al. Role of oxidative stress in the renal abnormalities induced by experimental hyperuricemia. Am J Physiol Renal Physiol 2008;295:F1134-41.

93. Baldwin W, McRae S, Marek G, et al. Hyperuricemia as a mediator of the proinflammatory endocrine imbalance in the adipose tissue in a murine model of the metabolic syndrome. Diabetes 2011;60:1258-69.

94. Kim SY, Guevara JP, Kim KM, et al. Hyperuricemia and coronary heart disease: a systematic review and meta-analysis. Arthritis Care Res (Hoboken) 2010;62:170-80.

95. Kim SY, Guevara JP, Kim KM, et al. Hyperuricemia and risk of stroke: a systematic review and meta-analysis. Arthritis Rheum 2009;61:885-92.

96. Grayson PC, Kim SY, LaValley M, et al. Hyperuricemia and incident hypertension: a systematic review and meta-analysis. Arthritis Care Res (Hoboken) 2011;63:102-10.

97. Lv Q, Meng XF, He FF, et al. High serum uric acid and increased risk of type 2 diabetes: a systemic review and meta-analysis of prospective cohort studies. PLOS ONE 2013;8:e56864.

98. Huang $\mathrm{H}$, Huang $\mathrm{B}, \mathrm{Li} \mathrm{Y}$, et al. Uric acid and risk of heart failure: a systematic review and meta-analysis. Eur J Heart Fail 2014:16:15-24.

99. Guthikonda S, Sinkey C, Barenz T, et al. Xanthine oxidase inhibition reverses endothelial dysfunction in heavy smokers. Circulation 2003;107:416-21.

100. Butler R, Morris AD, Belch JJ, et al. Allopurinol normalizes endothelial dysfunction in type 2 diabetics with mild hypertension. Hypertension 2000;35:746-51.

101. Doehner W, Schoene N, Rauchhaus M, et al. Effects of xanthine oxidase inhibition with allopurinol on endothelial function and peripheral blood flow in hyperuricemic patients with chronic heart failure: results from 2 placebo-controlled studies. Circulation 2002;105:2619-24.

102. Harzand A, Tamariz L, Hare JM. Uric acid, heart failure survival, and the impact of xanthine oxidase inhibition. Congest Heart Fail 2012;18:179-82. 
103. Waring WS, Adwani SH, Breukels O, et al. Hyperuricaemia does not impair cardiovascular function in healthy adults. Heart 2004;90:155-9.

104. Waring WS, McKnight JA, Webb DJ, et al. Lowering serum urate does not improve endothelial function in patients with type 2 diabetes. Diabetologia 2007:50:2572-9.

105. Waring WS, McKnight JA, Webb DJ, et al. Uric acid restores endothelial function in patients with type 1 diabetes and regular smokers. Diabetes 2006:55:3127-32.

106. Spitsin S, Markowitz CE, Zimmerman V, et al. Modulation of serum uric acid levels by inosine in patients with multiple sclerosis does not affect blood pressure. J Hum Hypertens 2010;24:359-62.

107. Lyngdoh $\mathrm{T}$, Vuistiner $\mathrm{P}$, Marques-Vidal $\mathrm{P}$, et al. Serum uric acid and adiposity: deciphering causality using a bidirectional Mendelian randomization approach. PLoS ONE 2012;7:e39321.

108. Pfister R, Barnes D, Luben R, et al. No evidence for a causal link between uric acid and type 2 diabetes: a Mendelian randomisation approach. Diabetologia 2011;54:2561-9.

109. Oikonen M, Wendelin-Saarenhovi M, Lyytikainen LP, et al. Associations between serum uric acid and markers of subclinical atherosclerosis in young adults. The cardiovascular risk in Young Finns study. Atherosclerosis 2012;223:497-503.

110. Dai X, Yuan J, Yao P, et al. Association between serum uric acid and the metabolic syndrome among a middle- and old-age Chinese population. Eur J Epidemiol 2013;28:669-76.

111. Palmer TM, Nordestgaard BG, Benn $\mathrm{M}$, et al. Association of plasma uric acid with ischaemic heart disease and blood pressure: mendelian randomisation analysis of two large cohorts. BMJ 2013;347:f4262.

112. Parsa A, Brown E, Weir MR, et al. Genotype-based changes in serum uric acid affect blood pressure. Kidney Int 2012;81:502-7.

113. Facchini F, Chen YD, Hollenbeck CB, et al. Relationship between resistance to insulin-mediated glucose uptake, urinary uric acid clearance, and plasma uric acid concentration. JAMA 1991;266: 3008-11.

114. Shen C, Guo Y, Luo W, et al. Serum urate and the risk of Parkinson's disease: results from a meta-analysis. Can J Neurol Sci 2013:40:73-9.

115. Gonzalez-Aramburu I, Sanchez-Juan P, Jesus S, et al. Genetic variability related to serum uric acid concentration and risk of Parkinson's disease. Mov Disord 2013;28:1737-40. 